\title{
Performance comparison of novel chemical agents in improving oil recovery from tight sands through spontaneous imbibition
}

\author{
Hai Huang ${ }^{1}$ Tayfun Babadagli ${ }^{1,2} \cdot$ Xin Chen $^{2} \cdot$ Huazhou Andy Li ${ }^{1,2}$
}

Received: 6 February 2019 / Published online: 23 September 2019

(c) The Author(s) 2019

\begin{abstract}
Tight sands are abundant in nanopores leading to a high capillary pressure and normally a low fluid injectivity. As such, spontaneous imbibition might be an effective mechanism for improving oil recovery from tight sands after fracturing. The chemical agents added to the injected water can alter the interfacial properties, which could help further enhance the oil recovery by spontaneous imbibition. This study explores the possibility of using novel chemicals to enhance oil recovery from tight sands via spontaneous imbibition. We experimentally examine the effects of more than ten different chemical agents on spontaneous imbibition, including a cationic surfactant (C12TAB), two anionic surfactants (O242 and O342), an ionic liquid (BMMIM BF4), a high pH solution $\left(\mathrm{NaBO}_{2}\right)$, and a series of house-made deep eutectic solvents (DES3-7, 9, 11, and 14). The interfacial tensions (IFT) between oil phase and some chemical solutions are also determined. Experimental results indicate that both the ionic liquid and cationic surfactant used in this study are detrimental to spontaneous imbibition and decrease the oil recovery from tight sands, even though cationic surfactant significantly decreases the oil-water IFT while ionic liquid does not. The high $\mathrm{pH} \mathrm{NaBO} 2$ solution does not demonstrate significant effect on oil recovery improvement and IFT reduction. The anionic surfactants (O242 and O342) are effective in enhancing oil recovery from tight sands through oil-water IFT reduction and emulsification effects. The DESs drive the rock surface to be more water-wet, and a specific formulation (DES9) leads to much improvement on oil recovery under counter-current imbibition condition. This preliminary study would provide some knowledge about how to optimize the selection of chemicals for improving oil recovery from tight reservoirs.
\end{abstract}

Keywords Spontaneous imbibition $\cdot$ Novel chemical agent $\cdot$ Water flooding $\cdot$ Tight sands

\section{Introduction}

Spontaneous imbibition is a common phenomenon encountered in subsurface reservoirs (Hatiboglu and Babadagli 2010). This phenomenon will become more significant in

Edited by Yan-Hua Sun

This paper was written while the second author was residing at Xi' an Shiyou University as a guest professor in 2018.

Xin Chen

xc11@ualberta.ca

1 College of Petroleum Engineering and Shaanxi Key Laboratory of Advanced Stimulation Technology for Oil and Gas Reservoirs, Xi' an Shiyou University, Xi' an 710065, People's Republic of China

2 School of Mining and Petroleum Engineering, Faculty of Engineering, University of Alberta, Edmonton T6G 1H9, Canada tight formations due to strong capillarity (Dutta et al. 2012; Wang et al. 2019). On the one hand, spontaneous imbibition would induce the loss of treatment fluids (such as fracturing fluids), resulting in increasing cost and formation damage (Dutta et al. 2012; Zhou et al. 2014). On the other hand, spontaneous imbibition can be utilized to recover oil from tight sands during the production stage. Therefore, careful selection of the chemicals used in fracturing fluids and subsequent chemical injection for oil recovery is a critical task.

Improving spontaneous imbibition may be an effective and practical strategy to enhance the oil production from unconventional resources. Based on the Young-Laplace equation described below, the capillary pressure $\left(P_{\mathrm{c}}\right)$ which drives the spontaneous imbibition is determined by wettability $(\theta)$, interfacial tension (IFT, $\sigma$ ), and pore radius $(r)$.

$P_{\mathrm{c}}=\frac{2 \sigma \cos \theta}{r}$ 
Therefore, wettability and interfacial tension alteration are considered as the two main mechanisms to promote the spontaneous imbibition (Alvarez and Schechter 2017). In strong water-wet reservoirs, the contact angle is much less than $90^{\circ}(\cos \theta>0)$, a higher IFT between oil and aqueous phase is beneficial to the spontaneous imbibition and oil recovery. In the reservoirs with weakly water-wet or neutral wet state, the gravity plays a more important role in producing oil and a lower IFT contributes to the oil recovery enhancement (Mohammed and Babadagli 2015). However, other factors such as oil properties, temperature, boundary condition, and flow type (such as co-current and countercurrent flow) remarkably control the imbibition rate and oil recovery (Babadagli 2001a; Fischer and Morrow 2005; Behbahani et al. 2006). Especially, for oil-wet tight reservoirs, spontaneous imbibition will occur only after wettability alteration while maintaining high oil-water IFT (Sheng 2017).

Based on the previous studies about tertiary and heavy oil recovery, the addition of chemicals to the injected water can help to further enhance oil recovery through capillary imbibition. Alkaline, surfactant, and polymer are the three major types of chemicals used in chemical flooding processes (Krumrine and Falcone 1983). While the polymer solution would decrease the imbibition rate due to high viscosity, many surfactants were proved to improve the oil imbibition within shales and tight formations (Ghedan and Poettmann 1991; Alvarez and Schechter 2017). Besides capillarity improvement, emulsification of surfactants can also help to drive the imbibition and increase the oil solubility (Zhang et al. 2009; Montes et al. 2018). However, different types of surfactants may lead to different levels of improvement on oil recovery. For example, Alvarez and Schechter (2017) stated that the anionic surfactant produces oil faster through imbibition than the nonionic and nonionic/cationic surfactants because of the wettability and IFT alterations. The internal olefin sulfonate (IOS) is one of the widely used and commercially available chemicals for oil production, and the variation of its carbon chain (length and degree of branching) helps to match different application conditions (Barnes et al. 2008; 2010). Furthermore, the cationic surfactant (C12TAB) can reduce the IFT at relatively low concentration, which may generate good economic returns (Roustaei 2014; Wei and Babadagli 2017). Therefore, this study aims to determine the effects of a cationic surfactant $(\mathrm{C} 12 \mathrm{TAB})$ and two anionic surfactants $(\mathrm{O} 242$ and $\mathrm{O} 342)$ on the spontaneous imbibition within tight-sand cores.

Alkaline materials are normally used in conjunction with other chemicals, because their solo use may result in solid precipitation issues. Alkali helps to mitigate the surfactant adsorption to core surface and further reduce the IFT within alkali-surfactant-polymer (ASP) flooding (Krumrine et al. 1982; Arihara et al. 1999). In addition, high $\mathrm{pH}$ solution is conducive to spontaneous imbibition within low-permeability rocks (Takahashi and Kovscek 2010). Besides traditional sodium carbonate $\left(\mathrm{Na}_{2} \mathrm{CO}_{3}\right)$ and sodium bicarbonate $\left(\mathrm{NaHCO}_{3}\right)$, sodium metaborate $\left(\mathrm{NaBO}_{2}\right)$ has been recently considered as a potential agent for EOR applications in conventional reservoir because it offers both high $\mathrm{pH}$ and effective wettability alteration (Zhang et al. 2009; Cao et al. 2015). Therefore, this study will compare the imbibition rate of the novel alkaline solution $\left(\mathrm{NaBO}_{2}\right)$ against that of the traditional one $\left(\mathrm{Na}_{2} \mathrm{CO}_{3}\right)$ in tight sands.

In recent years, aiming to control costs and further reduce residual oil, some novel chemical agents and methods have been developed for enhanced oil recovery (EOR) applications. Admittedly, salinity of flooding water affects not only the imbibition rate but also the performance of chemical agents (Karimi et al. 2016). But the optimized brine brings benefit to oil imbibition spontaneously (Shehata and El-Din 2015; Li et al. 2016). Moreover, with the advent of green chemistry technologies, some solvents (such as ionic liquids and deep eutectic solvents), which possess advantages of good availability, non-toxicity, good biodegradability, good recyclability, and environmental friendliness, have attracted the attention of petroleum researchers and engineers. Although ionic liquids (ILs) can reduce the water-oil interfacial tension considerably and help to create microemulsion as a surface active agent, the high price constrains its application in EOR (Lago et al. 2012; Zhang et al. 2012; Wei and Babadagli 2017). As low-cost materials, deep eutectic solvents (DES) are composed of two or more components that are capable of forming a eutectic mixture (Zhang et al. 2012). DES exhibits similar chemical and physical properties to the ionic liquid but is cheaper and more environmentally friendly. Due to the formation of eutectic, the melting point of DES is much lower than each of the individual components. Previous studies stated that DESs make the rock surface more water-wet, but neither reduce the IFT nor induce the formation of microemulsion. The DESs have been recently applied to improve the spontaneous imbibition of heavy oil and reduce formation damage (Shuwa et al. 2014; Al-Weheibi et al. 2015; Mohsenzadeh et al. 2015). In this study, a brine (3\% $\mathrm{NaCl}$ solution), an ionic liquid (1-butyl2,3-dimethylimidazolium tetrafluoroborate, BMMIM BF4), and a series of house-made DESs are tested for their potential effects on the spontaneous imbibition within tight-sand cores.

According to previous experiences and research studies, the combination of several chemical agents brings a dramatic boost on oil recovery owing to the synergistic effect (Krumrine and Falcone 1983; He and Xu 2018). However, more efforts as to the selection of proper (and cost effective) chemicals are needed for tight sands as the recovery mechanism will possibly be different from the other chemical applications summarized above. The spontaneous 
imbibition tests presented in this paper compare selected chemical agents and provide insights about how their potential is used in improving waterflood recovery from tight sands after fracturing. Therefore, it should be considered as a chemical screening test. This will lead to further detailed studies considering optimal concentrations and application limitations such as temperature and salinity.

\section{Experiments and materials}

\subsection{Materials}

The original tight sandstone cores used throughout the experiments were collected from the Yanchang Oilfield in Shaanxi, China. Their lengths are in the range of 5-7 cm. The average porosity and permeability of the cores are around $7 \%$ and $0.1 \mathrm{mD}$, respectively. The surface of these cores is weakly water-wet. The light crude oil used in the experiments was obtained from an oilfield in Canada, whose properties are similar to the crude oil in the Yanchang Oilfield. The total acid number (TAN), density, and viscosity of crude oil at $25^{\circ} \mathrm{C}$ and atmospheric pressure are $1.3 \mathrm{mg} / \mathrm{g}$, $0.88 \mathrm{~g} / \mathrm{cm}^{3}$, and $11 \mathrm{cP}$, respectively.

Flooding liquids were prepared by mixing chemicals in deionized water (DI water). Table 1 summarizes the chemical agents tested in this research. The brine used in this research was the $3 \% \mathrm{NaCl}$ solution. All the deep eutectic solvents (DES) were prepared in our laboratory, and the raw materials were purchased from Sigma-Aldrich. When making up a given DES, we first prepared two separate chemical solutions, each of which contains only an individual solvent with a concentration of $80 \%$; then, we mixed them up based on different molar ratios at $80{ }^{\circ} \mathrm{C}$ for $4 \mathrm{~h}$. The solutions were cooled under room condition and stored in a dark place.

\subsection{Experimental procedure}

Interfacial tensions between light crude oil and chemical solutions were measured under room temperature through the pendant drop device (shown in Fig. 1). An oil droplet was injected into the pressure cell, which has been filled up with the chemical solution, from the bottom needle. The drop shapes were captured by a camera, and the IFTs were obtained through the software analysis (DROPimage Advanced program). For each chemical agent, the IFTs were obtained at different concentrations.

Spontaneous imbibition tests were conducted using the designed imbibition cell as shown in Fig. 2. Before the tests, tight-sand cores were placed in a vacuum environment for $8 \mathrm{~h}$ to remove all the original fluids. The cores were saturated with the crude oil for more than 2 weeks under vacuum at room temperature. The cores saturated by oil were directly used in the co-current experiments. For the counter-current experiments, the cores were sealed by epoxy putty except for the bottom part. Under this boundary condition, only one side was open to flow. Saturated cores were placed in the cells containing different chemical solutions. The cells were put under the room temperature of $21^{\circ} \mathrm{C}$ and ambient

Table 1 List of tested chemicals

\begin{tabular}{|c|c|c|c|}
\hline Chemical type & Name/label & Composition & Manufacturer \\
\hline Cationic surfactant & C12TAB & Dodecyl trimethylammonium bromide & Sigma-Aldrich \\
\hline \multirow[t]{2}{*}{ Anionic surfactant } & $\mathrm{O} 242$ & $\begin{array}{l}\text { Internal olefin sulfonate (with a carbon number range of } \mathrm{C}_{20^{-}} \\
\mathrm{C}_{24} \text { ) }\end{array}$ & Shell Global Solutions International B.V. \\
\hline & $\mathrm{O} 342$ & $\begin{array}{l}\text { Internal olefin sulfonate (with a carbon number range of } \mathrm{C}_{19^{-}} \\
\mathrm{C}_{22} \text { ) }\end{array}$ & Shell Global Solutions International B.V. \\
\hline \multirow[t]{2}{*}{ Alkaline material } & $\mathrm{Na}_{2} \mathrm{CO}_{3}$ & Sodium carbonate & ACROS ORGANICS \\
\hline & $\mathrm{NaBO}_{2}$ & Sodium metaborate & ACROS ORGANICS \\
\hline Ionic liquid & BMMIM BF4 & 1-Butyl-2, 3-dimethylimidazolium tetrafluoroborate & Sigma-Aldrich \\
\hline \multirow[t]{8}{*}{ Deep eutectic solvent } & DES3 & Sodium carbonate and glycerin (1:2 molar ratio) & House-made \\
\hline & DES4 & Sodium carbonate and urea (1:2 molar ratio) & House-made \\
\hline & DES5 & Choline chloride and sodium carbonate (1:1 molar ratio) & House-made \\
\hline & DES6 & $\begin{array}{l}N, N \text {-bis (2-[bis(carboxymethyl)amino]ethyl) glycine and } \\
\text { dodecylbenzenesulfonic acid (1:10 molar ratio) }\end{array}$ & House-made \\
\hline & DES7 & $\begin{array}{l}\text { Choline chloride and dodecylbenzenesulfonic acid (1:1 molar } \\
\text { ratio) }\end{array}$ & House-made \\
\hline & DES9 & Sodium carbonate and sodium sulfate (1:2 molar ratio) & House-made \\
\hline & DES11 & $\begin{array}{l}\text { Sodium carbonate and 1-butyl-3-methylimidazolium tetra- } \\
\text { fluoroborate (5:1 molar ratio) }\end{array}$ & House-made \\
\hline & DES14 & Choline chloride and sodium carbonate (1:2 molar ratio) & House-made \\
\hline
\end{tabular}




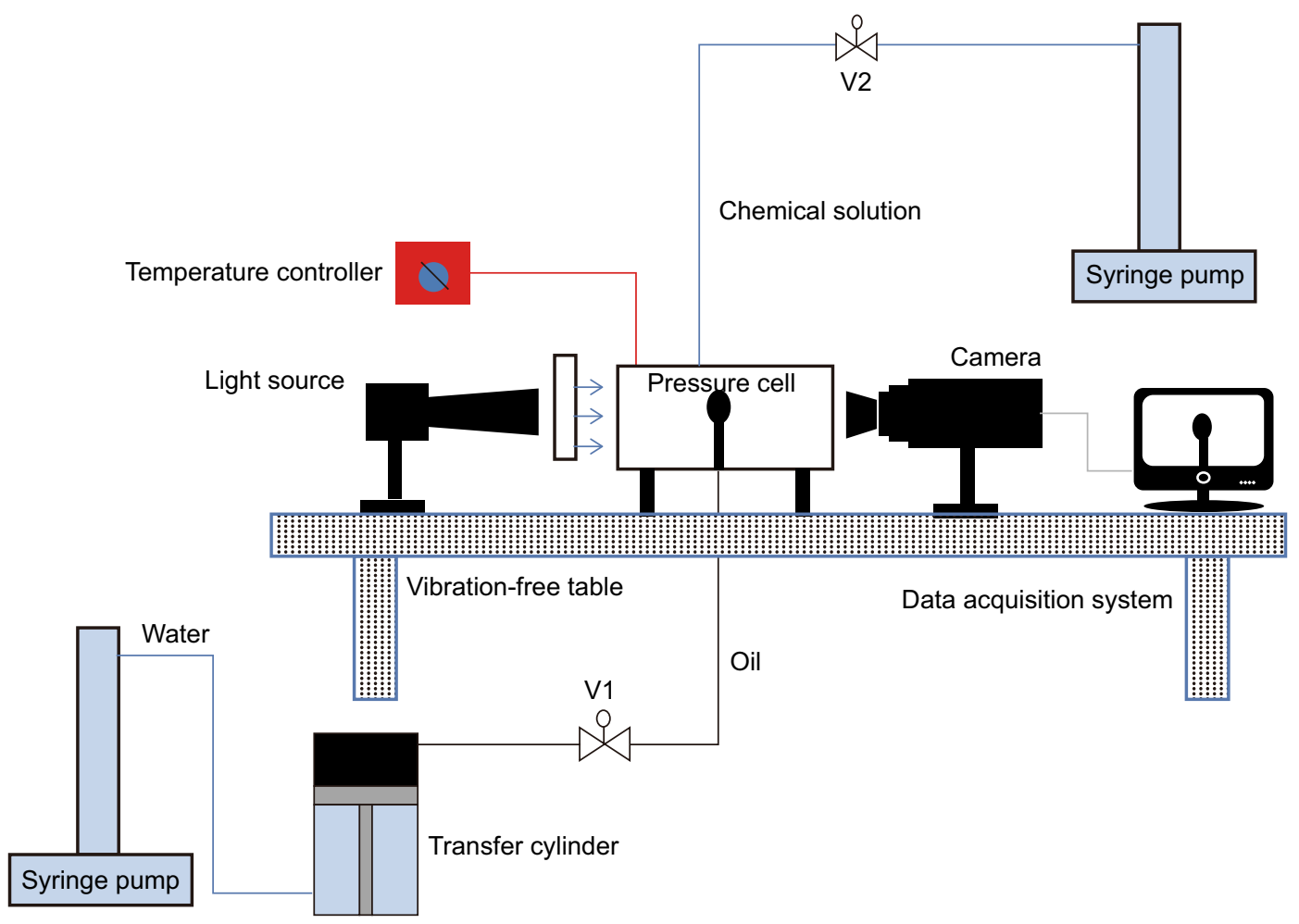

Fig. 1 Setup used to measure IFT (Wei and Babadagli 2017)

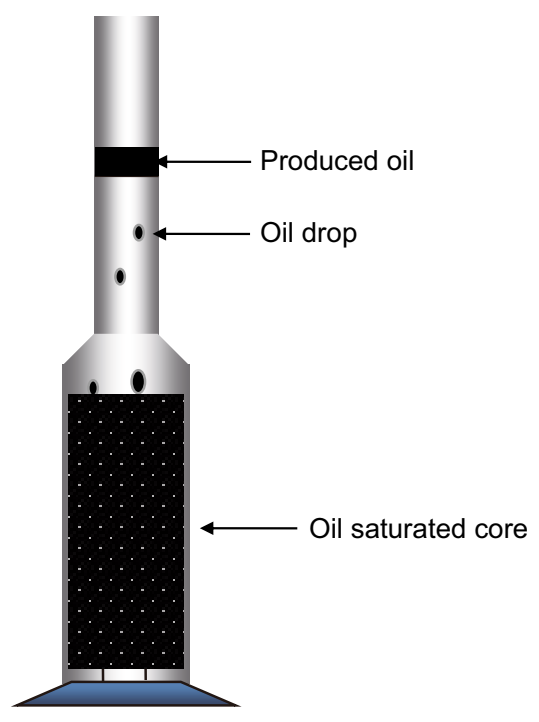

Fig. 2 Spontaneous imbibition setup used

pressure. A group of experiments were continued at a higher temperature $\left(50{ }^{\circ} \mathrm{C}\right.$, which is the original reservoir temperature, to test the performance of chemicals at reservoir conditions). Oil expelled from the cores was recorded versus time. Detailed data for spontaneous imbibition tests are summarized and presented in Figs. 4, 6, 8, 9 and 10. Only in the experiments of Fig. 9, we compared the oil recovery performances of chemicals under co-current and countercurrent conditions. For other experimental groups, the spontaneous imbibition tests were conducted under co-current condition.

\section{Results and discussion}

\subsection{Interfacial tension}

IFT alteration between surfactant solutions and crude oil is recognized as a crucial mechanism for enhancing oil recovery. In the previous experiments conducted by our research group, the $\mathrm{C} 12 \mathrm{TAB}$ and $\mathrm{NaBO}_{2}$ were proved to reduce the IFT between heavy oil and the aqueous phase, while ionic liquid (BMMIM BF4) increased the IFT (Wei and Babadagli 2017). Besides the properties of chemical solutions, the IFT is also influenced by many factors, including temperature, pressure, and the composition of oil (Wei and Babadagli 2016). Hence, this study tested the IFTs between the light crude oil and the solutions of $\mathrm{NaCl}, \mathrm{NaBO}_{2}$, ionic liquid, O342, DES6, DES14, and C12TAB with different concentrations, respectively.

Based on the IFT results shown in Fig. 3, the IFTs yielded by the $\mathrm{NaCl}$ solution and the ionic liquid solution are the same and show high values at different concentrations. This shows that $\mathrm{NaCl}$ and ionic liquid cannot help to reduce the 


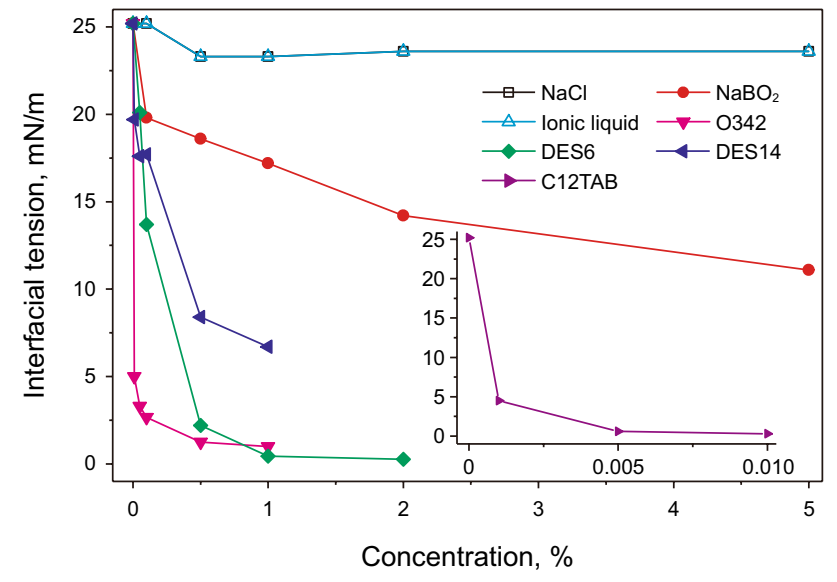

Fig. 3 Interfacial tension between light crude oil and chemical solutions with different concentrations

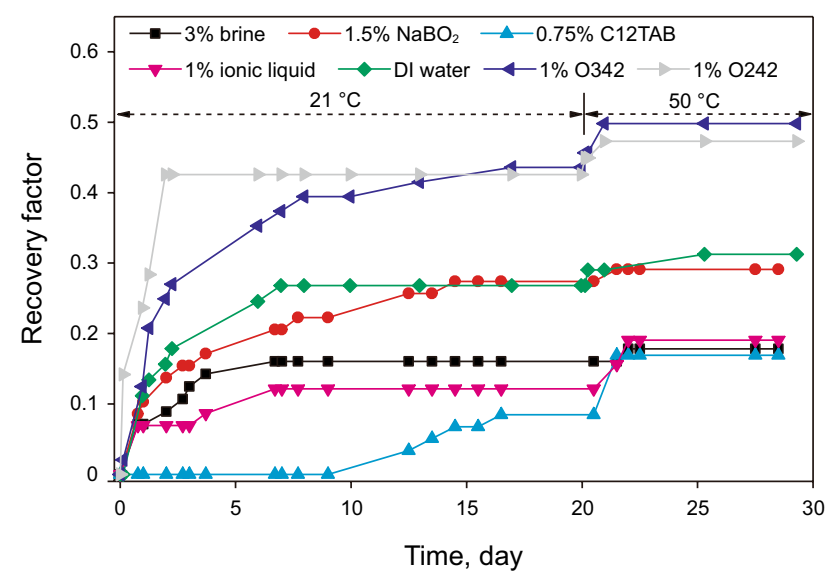

Fig. 4 Performance comparison of different chemicals in recovering oil from tight cores

IFT. Although the IFT yielded by $\mathrm{NaBO}_{2}$ solution will gradually decrease with increasing concentration, the IFT reduction is not as dramatic as those yielded by other chemicals. According to previous research, DESs impose little effect on the IFT. Nevertheless, both DES6 and DES14 exhibit stronger abilities on IFT reduction, and DES6 performs better. $\mathrm{O} 342$ can significantly decrease the IFT at relative low concentration, but the IFT yielded by $\mathrm{O} 342$ is higher than that yielded by DES6 at $1 \%$ concentration. It is worthwhile of noting that the IFT between the C12TAB solution and the light crude oil can achieve a very low level with extremely low $\mathrm{C} 12 \mathrm{TAB}$ concentration $(0.005 \%)$, so the $\mathrm{C} 12 \mathrm{TAB}$ displays the best performance on IFT reduction among those chemicals.

\subsection{Spontaneous imbibition}

Based on the above IFT results, different chemical agents exhibit distinct performances on altering IFT between oil and aqueous phase. The different properties of cores and saturated oil may also affect the EOR performances of these chemicals (Babadagli 2003). Therefore, this study tested the effects of $\mathrm{C} 12 \mathrm{TAB}, \mathrm{NaBO}_{2}$, ionic liquid, $\mathrm{O} 242$, and $\mathrm{O} 342$ on the spontaneous imbibition. Spontaneous imbibition tests with the use of deionized water (DI water) or brine were also conducted for comparison purposes. The concentrations of these chemical agents were determined based on the previous experimental results and literature recommendations (Barnes et al. 2010; Wei and Babadagli 2017). Experiments were conducted at $21^{\circ} \mathrm{C}$ at first 20 days and then heated to $50{ }^{\circ} \mathrm{C}$ until the end of test to examine the effect of temperature. The results are summarized in Fig. 4, and some representative photographs during the imbibition are shown in Fig. 5.

As seen in Fig. 4, recovery factors recorded during most of the experiments (except $0.75 \% \mathrm{C} 12 \mathrm{TAB}$ ) increase significantly within the first days, and then the increment in the recovery factor becomes mild, eventually leveling off after about 8 days. The accelerated spontaneous imbibition in the beginning is due to the more water-wet rock surface yielded by chemical additives. Note that $50{ }^{\circ} \mathrm{C}$ experiments were conducted to test the chemical potentials for EOR at reservoir conditions. All chemicals except $\mathrm{NaBO}_{2}$ showed an increment in oil recovery over a few days after temperature was increased to $50{ }^{\circ} \mathrm{C}$ from $21^{\circ} \mathrm{C}$. Before heating, the oil recoveries yielded by chemical solutions have remained stable. Rather, the increase in recovery indicates that those chemicals still work at this temperature.

Among these chemicals, the two anionic surfactants (1\% $\mathrm{O} 342$ and $1 \% \mathrm{O} 242$ ) exhibited the most effective performances on improving both the imbibition rate at early times and the ultimate oil recovery. According to Fig. 5b-d, the O242 and O342 solutions are much cloudier than the DI water because of the emulsification of internal olefin sulfonates. Moreover, the interface between the produced oil and $\mathrm{O} 342$ solution (Fig. 5d) is ambiguous and flat, which corroborates the IFT reduction effect yielded by the anionic surfactants. The $1.5 \% \mathrm{NaBO}_{2}$ solution did not affect the imbibition rate, even though $\mathrm{NaBO}_{2}$ makes the interface flat and moderately reduces the oil-water IFT (Fig. 5e). However, $3 \%$ brine, $1 \%$ ionic liquid, and $0.75 \% \mathrm{C} 12 \mathrm{TAB}$ decelerated the spontaneous imbibition rate and decreased the oil recovery. Previously, C12TAB was observed to reduce the oil-water IFT significantly, while ionic liquid decreases contact angle in oil/water/limestone systems (Roustaei 2014; Wei and Babadagli 2017). As opposed to the limestone cases, they were observed to be unsuitable for improving imbibition from tight sandstones. Interestingly, no 

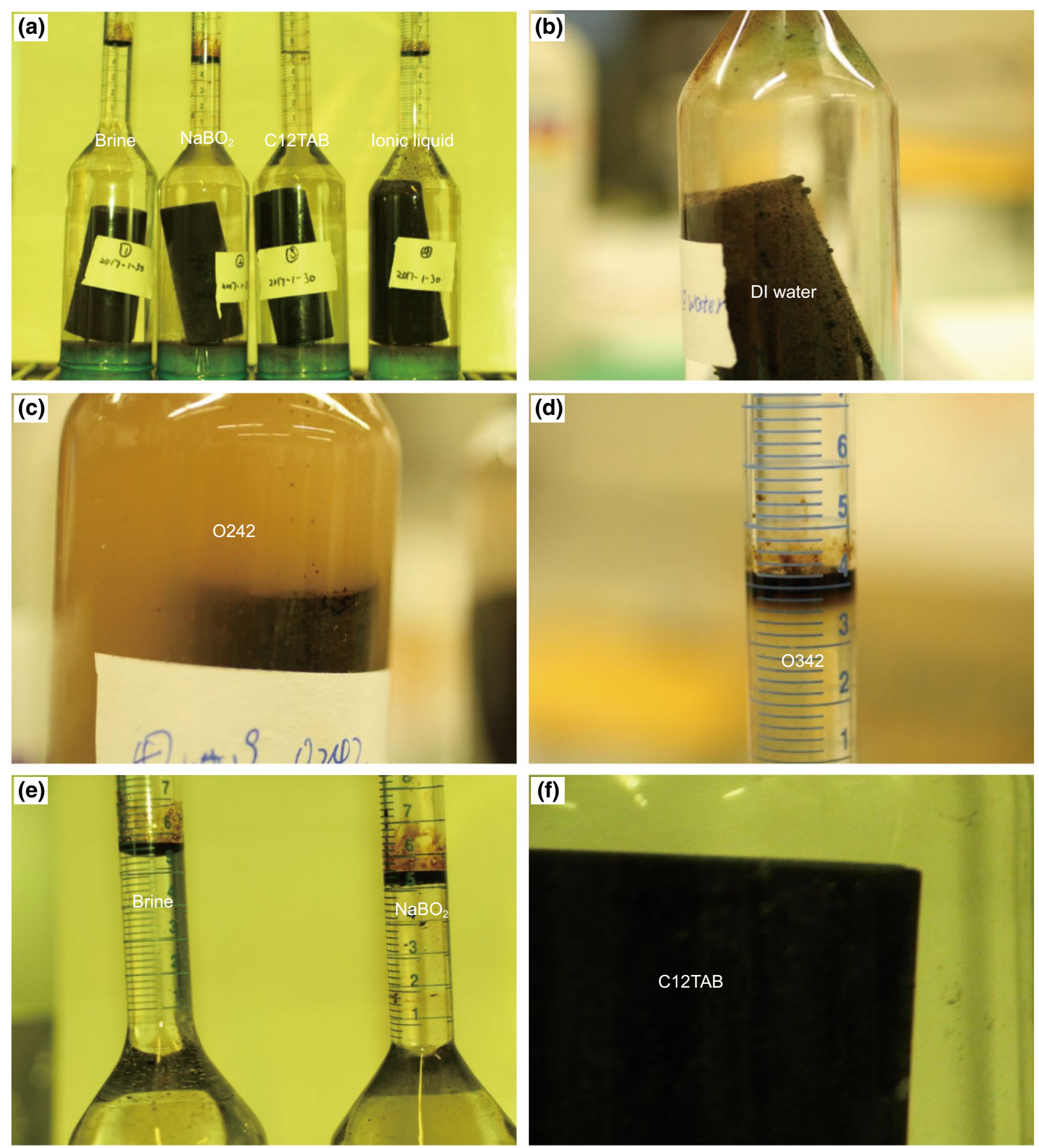

Fig. 5 Representative digital photographs captured during spontaneous imbibition tests using $\mathrm{C} 12 \mathrm{TAB}, \mathrm{O} 242, \mathrm{O}_{4} 42, \mathrm{NaBO}_{2}, \mathrm{BMMIM}^{\mathrm{B} F} 4$ (ionic liquid), brine, and DI water

oil produced spontaneously in the $\mathrm{C} 12 \mathrm{TAB}$ solution at first 9 days (Fig. 5f). Therefore, C12TAB may have a potential of being used for formation damage control in tight sandstone reservoirs. Note that brine gave a lower oil recovery than DI water, and the oil/water interface in brine is curved (Fig. 5e). Therefore, the salinity level of injected water used for such tight sandstone reservoir can be controlled (i.e., low salinity flooding) to improve recovery.

Deep eutectic solvent (DES) is a relatively low-cost novel green chemical that can prominently alter surface wettability (Shuwa et al. 2014; Mohsenzadeh et al. 2015). Sheng (2017) stated that wettability plays a dominant role in affecting the spontaneous imbibition in oil-wet tight reservoirs. Therefore, 


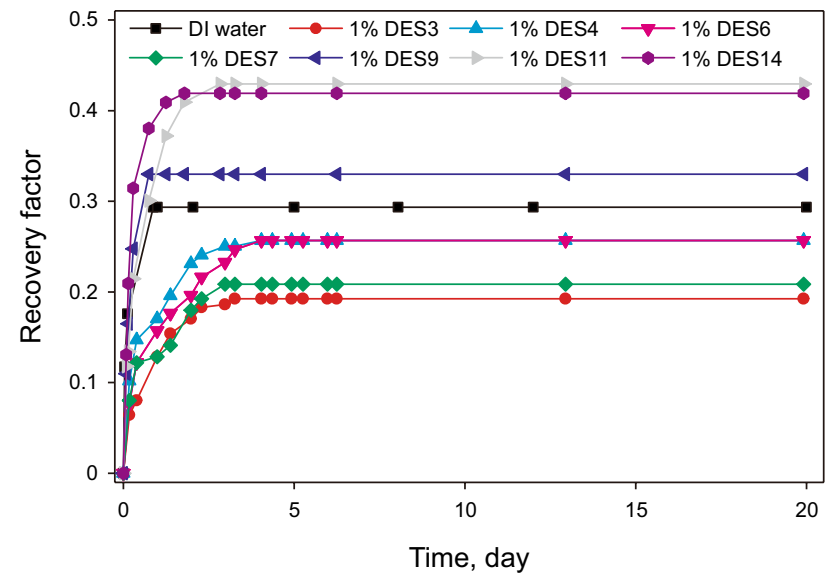

Fig. 6 Performance comparison of DES solutions in recovering oil from tight cores

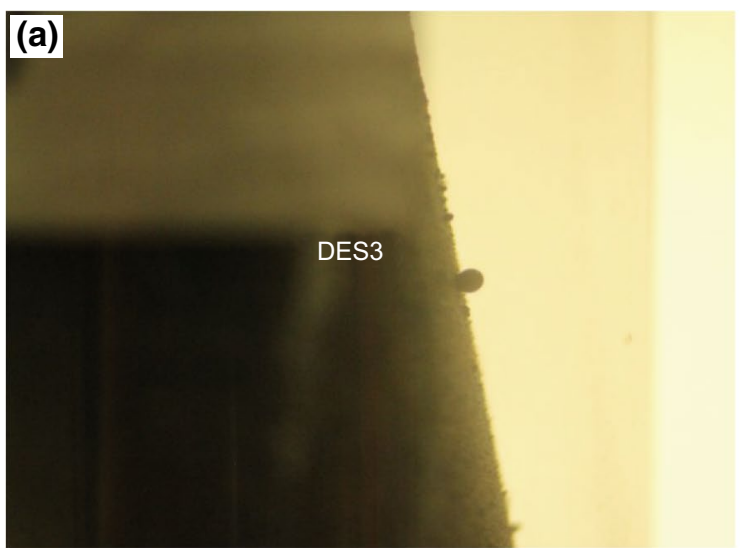

DESs are promising chemicals for enhancing oil recovery from tight sands, and a series of novel DESs has been developed for EOR purposes in our laboratory. The DESs samples were prepared as $1 \%$ solutions to compare their effects on the spontaneous imbibition. The test results on DESs are presented in Fig. 6, while some representative photographs are shown in Fig. 7.

One may observe that DES9, DES11, and DES14 accelerate the imbibition rate at the early times and improve ultimate oil recovery (Fig. 6). Especially, the improvements in oil recovery yielded by DES11 and DES14 are more obvious. On the contrary, use of DES3, DES4, DES6, and DES7 is detrimental to the oil recovery. Remarkably, based on the IFT results, both the DES6 and DES14 can effectively reduce the oil-water IFT but exhibit quite different EOR performances. This indicates that different types of DESs lead to drastically various effects on spontaneous imbibition,

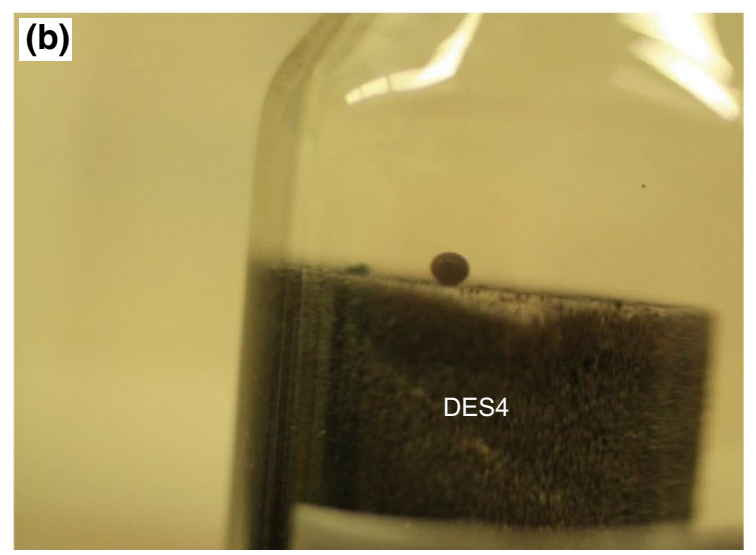

Fig. 7 Representative digital photographs captured during spontaneous imbibition tests using DES3 and DES4

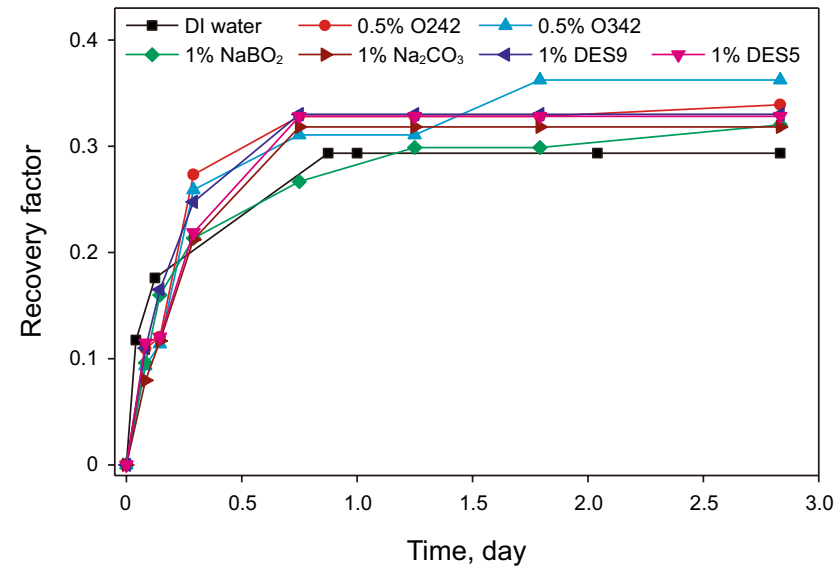

Fig. 8 Performance comparison of different chemicals in recovering oil from tight cores at the early age

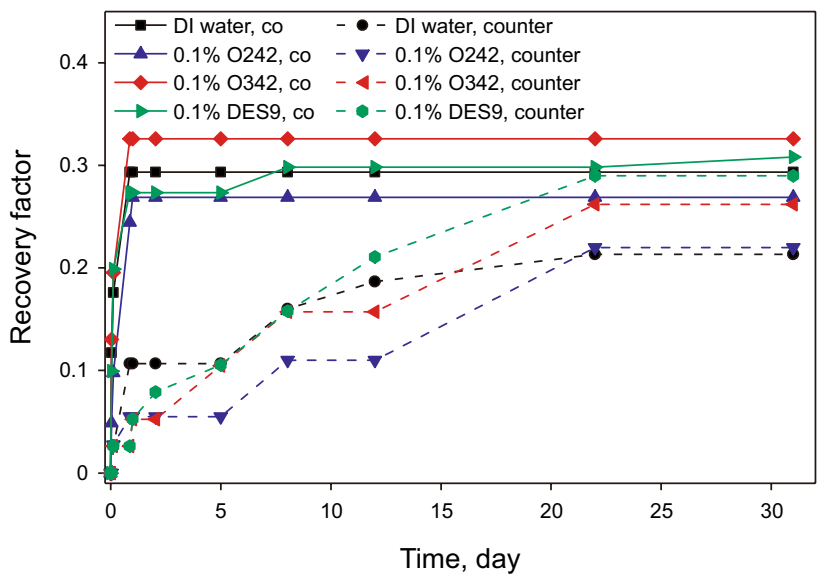

Fig. 9 Performance comparison of different chemicals in recovering oil from tight cores under different flow conditions (co: co-current, counter: counter-current) 


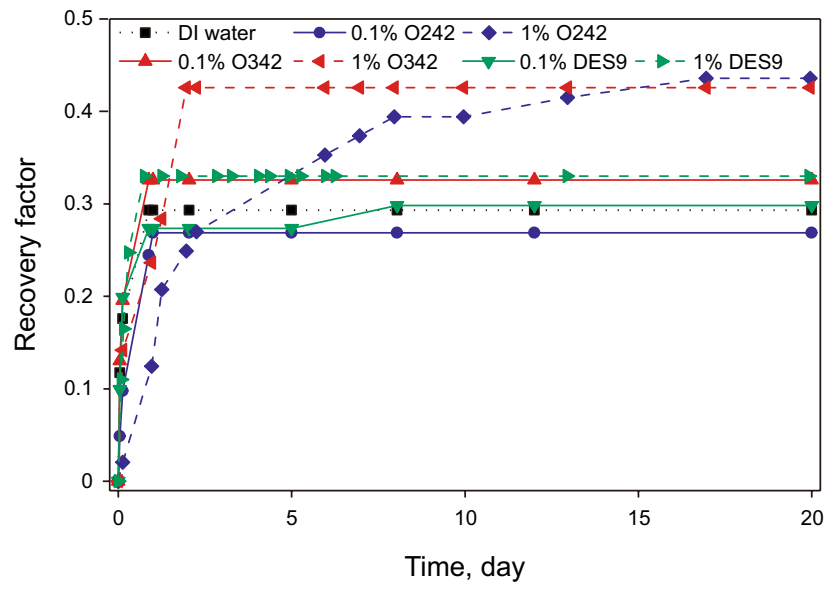

Fig. 10 Performance comparison of chemicals with different concentrations in recovering oil from tight cores

and the IFT alteration may be of little importance to the improvement in oil recovery from tight-sand core. Figure 7 shows that the oil bubbles seeping out of the cores in DESs solution are nearly spherical and have smaller contact area than those bubbles in DI water as shown in Fig. 5b. This indicates that DESs are able to render the weakly water-wet surface to a more strongly water-wet one, and the wettability alteration plays a primary role in oil recovery enhancement from tight sands.

In the analysis of spontaneous imbibition recovery curves, two parameters are critical: (1) ultimate recovery and (2) imbibition rate. The change in the latter early times is an indicator of wettability alteration, and as shown in Figs. 4 and 6, the recovery factor rises significantly in the early times for some of the chemicals compared to others. Therefore, we selected the best performing chemicals that improved the imbibition rate at early stages to compare their ability on oil recovery enhancement by wettability alteration. The comparison results are presented in Fig. 8 for the first 3 days. After about 1.3 days, the recovery factors yielded by all chemical solutions are higher than that by deionized water. Particularly, the recovery factors given by the two anionic surfactants (O342 and O242) and DES9 are significantly higher than others when the first $10 \mathrm{~h}$ of experiments are considered. This indicates that these chemicals exert a more obvious impact on EOR due to better wettability alteration. High $\mathrm{pH}$ solutions $\left(\mathrm{NaBO}_{2}\right.$ and $\mathrm{Na}_{2} \mathrm{CO}_{3}$ ) exhibited the slower imbibition rates. Alkalies are expected to alter IFT, especially in higher asphaltene content oil types, but this effect is seen in longer times, and their effect in wettability alteration (due to $\mathrm{pH}$ alteration) and IFT change is more obvious in carbonates (Babadagli et al. 2009).

Interestingly, those yielding accelerated imbibition rates in early times especially (O342 and O242) also showed higher ultimate recoveries, which are also controlled by lowered IFT. Hence, this type of surfactants is more suitable EOR agents compared to alkalis $\left(\mathrm{Na}_{2} \mathrm{CO}_{3}\right.$ and $\left.\mathrm{NaBO}_{2}\right)$ for the type of tight sandstones studied in this paper.

The type of interaction, i.e., co-current and countercurrent, plays a critical role in the oil recovery efficiency by spontaneous imbibition (Babadagli 2001b). Therefore, the oil recovery performances of three selected chemicals (O242, O342, and DES9) were compared for co-current and counter-current conditions. Note that the concentration of chemicals was further reduced to $0.1 \%$ to examine their effects under low concentrations in these experiments. Expectedly, the counter-current interaction yielded much slower imbibition rates, but final recoveries converged to those of co-current ones in considerably longer period (Fig. 9). O342 and DES9 showed the best performances for the counter-current case as similar to the co-current one. DI water yielded the biggest difference between co- and counter-current cases. In any event, counter-current imbibition performance was improved by the additives in the same manner (at least qualitatively) as in the co-current one. In particular, DES9 improved the ultimate oil recovery significantly under counter-current conditions, while $\mathrm{O} 242$ and $\mathrm{O} 342$ demonstrated limited improvements on ultimate oil recovery. The surface wettability would play a pivotal role in counter-current imbibition (Hatiboglu and Babadagli 2007, 2010). Therefore, DESs provide a significant improvement on imbibitionbased oil recovery under complicated boundary conditions because of their stronger ability to alter the rock-surface wettability.

Finally, we compared the performances of the three chemicals (O242, O342, and DES9) with $0.1 \%$ and $1 \%$ concentrations, respectively, in recovering oil (under co-current condition). As shown in Fig. 10, at a low concentration, the oil recovery improvement yielded by these chemicals was reduced significantly. Only O342 and DES9 slightly improved the ultimate oil recovery. According to Barnes et al. (2010), $\mathrm{O} 342$ and $\mathrm{O} 242$ at $0.3 \%-2 \%$ are active for EOR in the aqueous phase. In our experiments, the concentration of $\mathrm{O} 242$ and $\mathrm{O} 342$ (i.e., $0.1 \%$ ) is far lower than the recommended dosage, resulting in the poor performance on oil recovery. Further studies are needed to obtain the optimal concentrations of the recommended chemical types considering the adsorption, emulsion generation capability, and the cost.

\section{Conclusions}

In order to improve the oil recovery from tight sands after fracturing, the effects of more than ten novel chemical agents on the spontaneous imbibition were tested, including 
a cationic surfactant (C12TAB), two anionic surfactants (O242, O342), an ionic liquid (BMMIM BF4), a high $\mathrm{pH}$ solution $\left(\mathrm{NaBO}_{2}\right)$, and eight house-made deep eutectic solvents (DES3-7, 9, 11, and 14). The major experimental findings can be summarized as follows:

- Both the ionic liquid (BMMIM BF-4) and cationic surfactant $(\mathrm{C} 12 \mathrm{TAB})$ yielded worse spontaneous imbibition performances (slower imbibition rates and lower ultimate recoveries) than brine, although cationic surfactant could significantly decrease the oil-water IFT while ionic liquid did not;

- The anionic surfactants (O242, O342) were effective in enhancing oil recovery from tight sands through wettability alteration, IFT reduction, and emulsification effects;

- The high $\mathrm{pH} \mathrm{NaBO}_{2}$ solution exhibited a moderate performance in reducing IFT, but could not lead to significant improvement on oil recovery;

- Different types of DESs led to drastically different effects on the spontaneous imbibition, making it highly necessary to properly formulate the DES types for a given tight-sand type prior to field implementation;

- The anionic surfactant $\mathrm{O} 342$ yielded the greatest impact on improving imbibition-based oil recovery under cocurrent conditions, while DES9 performed the best under counter-current conditions because of its strong ability on rock-surface wettability alteration.

The experimental findings in this study indicate that the effects of chemical agents on the oil recovery from tightsand cores may be different from the previous studies conducted for "conventional" cores. It is hoped that the initial observations presented in this paper will be useful in selecting proper type and characteristics of the injected chemical and also shed light into the further research on the optimal design of the chemical flooding processes in tight sands after fracturing.

Acknowledgements This research was conducted under the second author's (TB) NSERC Industrial Research Chair in Unconventional Oil Recovery (industrial partners are Petroleum Development Oman, Total E\&P Recherché Développement, SIGNa Oilfield Canada, Husky Energy, Saudi Aramco, Devon, APEX Eng. and BASF), with additional support provided through a NSERC Discovery Grant (No: RES0011227) to T. Babadagli and a NSERC Discovery Grant (No: NSERC RGPIN 05394) to H. Li. We gratefully acknowledge these supports. H. Huang is also grateful for the financial supports provided by National Natural Science Foundation of China (No: 51874240), National Science and Technology Major Project (No: 2016ZX05047003-004), and the Key Laboratory Fund of Education Department of Shaanxi Province (No: 15JS086). X. Chen also greatly acknowledges the Ph.D. Scholarship from the China Scholarship Council (CSC) (201806450029) for the financial support. Finally, we would like to extend our appreciation to Lixing Lin for his intensive work during the preparation of core samples and collection of experimental data.
Open Access This article is distributed under the terms of the Creative Commons Attribution 4.0 International License (http://creativeco mmons.org/licenses/by/4.0/), which permits unrestricted use, distribution, and reproduction in any medium, provided you give appropriate credit to the original author(s) and the source, provide a link to the Creative Commons license, and indicate if changes were made.

\section{References}

Alvarez JO, Schechter DS. Wettability alteration and spontaneous imbibition in unconventional liquid reservoirs by surfactant additives. SPE Res Eval Eng. 2017;20(1):107-17. https://doi. org/10.2118/177057-PA.

Al-Weheibi I, Al-Hajri R, Al-Wahaibi Y, Jibril B, Mohsenzadeh A. Oil recovery enhancement in Middle East heavy oil field using malonic acid based deep eutectic solvent. In: SPE Middle East oil \& gas show and conference, 8-11 March, Manama, Bahrain; 2015. https://doi.org/10.2118/172592-MS.

Arihara N, Yoneyama T, Akita Y, Lu X. Oil recovery mechanisms of alkali-surfactant-polymer flooding. In: SPE Asia Pacific oil and gas conference and exhibition, 20-22 April, Jakarta, Indonesia; 1999. https://doi.org/10.2118/54330-MS.

Babadagli T. Dynamics of capillary imbibition when surfactant, polymer, and hot water are used as aqueous phase for oil recovery. $\mathrm{J}$ Colloid Interface Sci. 2001a;246:203-13. https://doi.org/10.1006/ jcis.2001.8015.

Babadagli T. Scaling of co-current and counter-current capillary imbibition for surfactant and polymer injection in naturally fractured reservoirs. SPE J. 2001b;6(4):465-78. https://doi. org/10.2118/74702-PA.

Babadagli, T. Analysis of oil recovery by spontaneous imbibition of surfactant solution. In: SPE international improved oil recovery conference in Asia Pacific, 20-21 October, Kuala Lumpur, Malaysia; 2003. https://doi.org/10.2523/84866-MS.

Babadagli T, Sahin S, Kalfa U, Celebioglu D, Karabakal U, Topguder NN. Evaluation of steam injection potential and improving ongoing $\mathrm{CO}_{2}$ injection of the Bati Raman field, Turkey. J Pet Sci Eng. 2009;68(1-2):107-17. https://doi.org/10.1016/j.petro 1.2009.06.015.

Barnes JR, Dirkzwager H, Smit JR, Smit J, On A, Navarrete RC, et al. Application of internal olefin sulfonates and other surfactants to EOR. Part 1: structure-performance relationships for selection at different reservoir conditions. In: SPE improved oil recovery symposium, 24-28 April, Tulsa, Oklahoma, USA; 2010. https://doi.org/10.2118/129766-MS.

Barnes JR, Smit JP, Smit JR, Shpakoff G, Raney KH, Puerto M. Development of surfactants for chemical flooding at difficult reservoir conditions. In: SPE/DOE improved oil recovery symposium, 19-23 April, Tulsa, Oklahoma, USA; 2008. https://doi. org/10.2118/113313-MS.

Behbahani HS, Donato GD, Blunt MJ. Simulation of counter-current imbibition in water-wet fractured reservoirs. J Pet Sci Eng. 2006;50:21-39. https://doi.org/10.1016/j.petrol.2005.08.001.

Cao N, Mohammed MA, Babadagli T. Wettability alteration of heavy-oil/bitumen containing carbonates using solvents, high $\mathrm{pH}$ solutions and nano/ionic liquids. In: Offshore technology conference, 27-29 October, Rio de Janeiro, Brazil; 2015. https ://doi.org/10.4043/26068-MS.

Dutta R, Lee CH, Odumabo S, Ye P, Walker SC, Karpyn ZT, et al. Quantification of fracturing fluid migration due to spontaneous imbibition in fractured tight formations. In: Americas 
unconventional resources conference, 5-7 June, Pittsburgh, Pennsylvania, USA; 2012. https://doi.org/10.2118/154939-MS.

Fischer H, Morrow NR. Spontaneous imbibition with matched liquid viscosities. In: SPE annual technical conference and exhibition, 9-12 October, Dallas, Texas, USA; 2005. https://doi. org/10.2118/96812-MS.

Ghedan SG, Poettmann FH. Effect of polymers on the imbibition process: a laboratory study. SPE Reserv Eng. 1991;6(1):84-90. https://doi.org/10.2118/20244-PA.

Hatiboglu CU, Babadagli T. Oil recovery by counter-current spontaneous imbibition: effects of matrix shape factor, gravity, IFT, oil viscosity, wettability, and rock types. J Pet Sci Eng. 2007;59:106-22. https://doi.org/10.1016/j.petrol.2007.03.005.

Hatiboglu CU, Babadagli T. Experimental and visual analysis of co- and counter-current spontaneous imbibitions for different viscosity ratios, interfacial tensions, and wettabilities. J Pet Sci Eng. 2010;70:214-28. https://doi.org/10.1016/j.petro 1.2009.11.013.

$\mathrm{He} \mathrm{K}, \mathrm{Xu} \mathrm{L}$. Unique mixtures of anionic/cationic surfactants: a new approach to enhance surfactant performance in liquids-rich shale reservoirs. SPE Prod Oper. 2018;33(2):363-70. https://doi. org/10.2118/184515-PA.

Karimi M, Al-Maamari RS, Ayatollahi S, Mehranbod B. Wettability alteration and oil recovery by spontaneous imbibition of low salinity brine into carbonates: impact of $\mathrm{Mg}^{2+}, \mathrm{SO}_{4}{ }^{2-}$ and cationic surfactant. J Pet Sci Eng. 2016;147:560-9. https://doi.org/10.1016/j. petrol.2016.09.015.

Krumrine PH, Falcone JS, Campbell TC. Surfactant flooding 1: the effect of alkaline additives on IFT, surfactant adsorption, and recovery efficiency. SPE J. 1982;22(4):503-13. https://doi. org/10.2118/8998-PA.

Krumrine PH, Falcone JS. Surfactant, polymer, and alkali interactions in chemical flooding processes. In: International symposium on oilfield and geothermal chemistry, 1-3 June, Denver, Colorado, USA; 1983. https://doi.org/10.2118/11778-MS.

Lago S, Rodriguez H, Khoshkbarchi MK, Sotoa A, Arce A. Enhanced oil recovery using the ionic liquid trihexyl (tetradecyl) phosphonium chloride: phase behaviour and properties. RSC Adv. 2012;2:9392-7. https://doi.org/10.1039/c2ra21698a.

Li X, Teklu TW, Abass H, Cui Q. The impact of water salinity/surfactant on spontaneous imbibition through capillarity and osmosis for unconventional IOR. In: Unconventional resources technology conference, 1-3 August, San Antonio, Texas, USA; 2016. https:// doi.org/10.15530/URTEC-2016-2461736.

Mohammed M, Babadagli T. Wettability alteration: a comprehensive review of materials/methods and testing the selected ones on heavy-oil containing oil-wet systems. Adv Colloid Interface Sci. 2015;220:54-77. https://doi.org/10.1016/j.cis.2015.02.006.

Mohsenzadeh A, Al-Wahaibi Y, Al-Hajri R, Jibril B, Joshi S, Pracejus $\mathrm{B}$. Investigation of formation damage by deep eutectic solvents as a new EOR agents. In: SPE European Formation damage conference and exhibition, 3-5 June, Budapest, Hungary; 2015. https:// doi.org/10.2118/174257-MS.

Montes J, Blin N, Alvarez AE, Panadero A, Rodriguez R, Coca M, et al. Novel anionic surfactant formulation for high temperature carbonate reservoirs. In: SPE EOR conference at oil and gas West Asia, 26-28 March, Muscat, Oman; 2018. https://doi. org/10.2118/190353-MS.

Roustaei A. An evaluation of spontaneous imbibition of water into oil-wet carbonate reservoir cores using nanofluid. Petrophysics. 2014;55(1):31-7.

Shehata AM, El-Din HAN. Spontaneous imbibition study: effect of connate water composition on low-salinity waterflooding in sandstone reservoirs. In: SPE western regional meeting, 27-30 April, Garden Grove, California, USA; 2015. https://doi. org/10.2118/174063-MS.

Sheng JJ. What type of surfactants should be used to enhance spontaneous imbibition in shale and tight reservoirs? J Pet Sci Eng. 2017;159:635-43. https://doi.org/10.1016/j.petrol.2017.09.071.

Shuwa SM, Jibril BY, Al-Wahaibi YM, Al-Hajri R. Heavy-oil-recovery enhancement with choline chloride/ethylene glycol-based deep eutectic solvent. SPE J. 2014;20(1):79-87. https://doi. org/10.2118/172499-PA.

Takahashi S, Kovscek AR. Spontaneous countercurrent imbibition and forced displacement characteristics of low-permeability, siliceous shale rocks. J Pet Sci Eng. 2010;71:47-55. https://doi. org/10.1016/j.petrol.2010.01.003.

Wang J, Liu H, Qian G, Peng Y, Gao Y. Investigations on spontaneous imbibition and the influencing factors in tight oil reservoirs. Fuel. 2019;236:755-68. https://doi.org/10.1016/j.fuel.2018.09.053.

Wei Y, Babadagli T. Selection of proper chemicals to improve the performance of steam based thermal applications in sands and carbonates. In: SPE Latin America and Caribbean heavy and extra heavy oil conference, 19-20 October, Lima, Peru; 2016. https:// doi.org/10.2118/181209-MS.

Wei Y, Babadagli T. Selection of new generation chemicals as steam additive for cost effective heavy-oil recovery applications. In: SPE Canada heavy oil technical conference, 15-16 February, Calgary, Alberta, Canada; 2017. https://doi.org/10.2118/184975-MS.

Zhang J, Nguyen QP, Flaaten AK, Pope GA. Mechanisms of enhanced natural imbibition with novel chemicals. SPE Res Eval Eng. 2009;12(6):912-20. https://doi.org/10.2118/113453-PA.

Zhang Q, Vigier KDO, Royer S, Jérôme F. Deep eutectic solvents: syntheses, properties and applications. Chem Soc Rev. 2012;41:710846. https://doi.org/10.1039/c2cs35178a.

Zhou Z, Hoffman B, Bearinger D, Li X. Experimental and numerical study on spontaneous imbibition of fracturing fluids in shale gas formation. In: SPE/CSUR unconventional resources conference, 30 September-2 October, Calgary, Alberta, Canada; 2014. https ://doi.org/10.2118/171600-MS. 